\title{
Erratum to: Foot-turistic multimedia: designing interactive multimedia installations for shoe shops
}

\author{
Pedro Campos • Miguel Campos • Paulo Freitas • \\ Joaquim Jorge
}

\section{Erratum to: Multimed Tools Appl DOI 10.1007/s11042-011-0854-6}

The original version of this article unfortunately contained a mistake. There should be an "Acknowledgements" section with the following text: "This work was supported by FCT (INESC-ID multiannual funding) through the PIDDAC Program funds".

The online version of the original article can be found at http://dx.doi.org/10.1007/s11042-011-0854-6.

P. Campos $\cdot$ J. Jorge

Computer Science and Engineering Department (DEI) of the School of Engineering (IST),

Technical University of Lisbon, Lisbon, Portugal

P. Campos $(\bowtie)$

University of Madeira, Funchal, Portugal

e-mail: pcampos@uma.pt

M. Campos $\cdot$ P. Freitas

WowSystems, Madeira, Portugal 